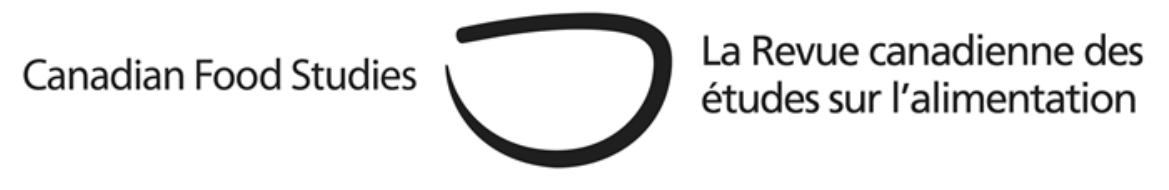

Field Report

\title{
From tensions to transformation: Teaching food systems in a graduate dietetics course
}

Eric $\mathrm{Ng}^{*}$ and Donald C. Cole

University of Toronto

\section{Abstract}

Dietitians are deeply embedded within food systems, so food systems concepts are becoming an essential component of dietetic education in Canada. Yet how can we, as educators, better prepare future dietitians to embrace the complexity of food systems and be forces of change towards equity? In an effort to explore this question in a practical way, we integrated food systems concepts into a mandatory course of a public health graduate dietetics program. This field report shares our experiences teaching food systems over five years based on our notes kept, student feedback, and course evaluations. Our learnings have been in three key areas: intentions, facilitation, and tensions.

We recognized that teaching about food systems is value-laden. Hence, we have been explicit with the students about our positionality and our intentions in designing the course, partly to meet the management of food systems competency requirements, but also to stimulate thinking about alternative options for purpose, structures, and processes in food systems. Our facilitation approaches aimed to foster a critical consciousness towards social justice and systems change. Using teaching and evaluation methods such as experiential learning, community projects, and reflection assignments, students have encountered the complexity of food systems and the challenges-opportunities they pose. As educators, we have grappled with the tensions of challenging dominant positivist discourses in public health nutrition. Politicized topics such as migrant farm-worker regimes, industrial food production, regulation of food marketing, and mitigation of the impact of colonization have generated debates in the classroom about the role 
and scope of dietetic practice. Most students have situated themselves more explicitly within a food system, and some began to question hidden structures of power. While it remains challenging to address this breadth within the constraints of one course, we believe it worthwhile to model and stimulate critical reflexivity among the next generation of dietitians as critical food learners-teachers themselves. Even though the course is no longer offered using this food systems approach, course components can be integrated throughout the dietetic curriculum.

Keywords: Food systems; andragogy; critical dietetics; public health nutrition; graduate education

\section{Introduction}

With growing social inequalities amplified locally and globally through times of crises, sustained examination of the inequities within our food systems is vital for fostering social action for change. As food educators, how we teach and talk about food contributes to the potential for change in our food systems (Sumner, 2015), especially among future generations of public health professionals such as dietitians (Wegener, 2018).

Dietitians increasingly recognize the interconnectedness between nutrition and our food systems. Shifting our food systems towards sustainability is crucial to our collective health. Embedded within food systems, dietitians provide nutrition advice in communities, work with governments to shape food environments, advocate for policies that support security, and manage institutional foodservice operations (Carlsson et al., 2020). According to the Role Paper from Dietitians of Canada on Sustainable Food Systems (Carlsson et al., 2020), dietitians are called upon to promote food systems change towards sustainability and equity through collective action. Yet how might we prepare future dietitians better for such a task (Wegener, 2018)?

The purpose of this field report is to critically reflect on our experience teaching a required graduate course on the management of community food systems in a graduate dietetics program over five years. We start by providing an overview of the landscape of food system education, focusing on dietetics. Turning to the course and our approach to transformative learning, we briefly discuss methods before sharing our reflections on key learning areas emerging from our teaching experience (intentions, facilitation, and tensions) and explore the challenges we encountered as food educators.

Due to significant growth in program enrolment in 2019, changes to the overall curriculum were made to accommodate increased demands for the practical training opportunities to meet mandatory dietetic competencies requirements. Consequently, this course was offered for the last time in the format we will discuss here in the Fall term of 2019. This curriculum change provided us with an opportunity to learn from our teaching approach, to reflect on our experiences, and to explore ways to integrate course components into the curriculum beyond the scope of one course. 


\section{Landscape of food system education}

Surveys of dietetic educators (Carlsson et al., 2019; Harmon et al., 2011) have shown that they are motivated to include sustainability into dietetic education; however, they feel unprepared in the field of sustainable food systems. This trend is demonstrated by more dietetic education programs incorporating food systems into their curriculum in a variety of ways, including some programs designing dedicated courses on the topic (Wegener et al., 2018). Yet, to engage students in thinking about sustainable food systems, dietetic educators are asked to confront complexity, debates, and uncertainty. Teaching such complex and contested topics requires knowing not only the "content of we what teach but also paying attention to the way we teach" (Galt et al., 2012, p.43).

Reflecting on food pedagogies can be useful for dietitians, who, as health professionals, engage in food systems education. Articulated food pedagogies propel us to locate learning and teaching about food systems within "wider social, cultural, and political relations of power" (Flowers \& Swan, 2012, p.425). This recognition of power within our food systems, and within food systems education itself, forms a key building block for teaching food systems critically. As for other health professional education (Halman et al., 2017), by considering how dietetic curriculum and educators themselves shape our future profession, training programs can better foster compassion and facilitate social change towards sustainability and equity.

The University of Toronto Master of Public Health - Nutrition \& Dietetics Program is a graduate-level dietetic education program situated in the Dalla Lana School of Public Health in partnership with the University Health Network and Toronto Public Health (Dalla School of Public Health, University of Toronto, 2020). Our students come from diverse backgrounds, having completed an undergraduate degree in nutrition. They also have experiences in many dietetic practice areas through research projects, volunteering in community organizations, and paid work in food services. Throughout their program, students develop specific dietetic training competencies to be qualified to write the dietetic registration exam to practice as dietitians in Canada (Dietitians of Canada, 2020).

\section{Course, instructors, and teaching approach}

Foundations of Practice III was the third of a series of three mandatory semester courses in dietetic practice covering the five domains of the Integrated Competencies for Dietetic Education and Practice (ICDEPs, see Partnership for Dietetic Education and Practice, 2013).

Although initially designed to facilitate practical experiences for students to achieve dietetic training competencies in the management domain (PDEP, 2013), it evolved to incorporate emerging food systems concepts as essential to extend the scope of dietetics practice adequately. 
The course structure covered various stages involved in the food system: from inputs and production, to processing and distribution, preparation and consumption, and food waste utilization and disposal. Different course components approached different stages and the overall system in different ways (see Table 1). Each week a guest speaker from a particular food systems organization would cover a specific topic e.g., a member of the Agricultural Workers' Alliance on the Seasonal Agricultural Workers Program which brings temporary foreign workers to work on Canadian farms during the agricultural season, with an associated host of challenges to their food security (Weiler et al., 2017). Field visits were arranged with such organizations as well e.g., the publicly funded Ontario Food Terminal, where many small to medium-sized retailers and restaurants buy fresh produce from farmers and distributors, and which regularly donates produce to food banks (Ferro-Townsend, 2011). In-class sessions included interactive activities, such as laying out the commodity chain for a particular food globally. Students also undertook a project with a community organization, e.g., exploring the feasibility and options for a community oven at an urban farm involving racialized community participants. A "bookended" Food Conception Reflection paper was used for students to articulate changes in their understanding of the complexity of food systems and their place within them (see below in findings).

Table 1: Course components and examples (2015 to 2019)

\begin{tabular}{|c|c|}
\hline Component & Examples \\
\hline Weekly Speakers' Topics & $\begin{array}{l}\text { Municipal food policy } \\
\text { Indigenous food systems } \\
\text { seasonal agricultural workers program } \\
\text { Local food procurement in an institutional food service } \\
\text { environmental contaminants and food pathways } \\
\text { Food marketing to children } \\
\text { Climate-friendly diets }\end{array}$ \\
\hline Field Visits & $\begin{array}{l}\text { Community farm } \\
\text { Community hub \& garden } \\
\text { Ontario food terminal } \\
\text { Large national food retailer } \\
\text { Local board of health \& food policy council }\end{array}$ \\
\hline In-Class Experiential Learning & $\begin{array}{l}\text { Community food mapping } \\
\text { Food commodity distribution chain exploration } \\
\text { Dietary greenhouse gas emissions calculation }\end{array}$ \\
\hline Community-Based Projects & $\begin{array}{l}\text { Community food bike delivery project } \\
\text { Letter writing advocacy campaign for community food security } \\
\text { Community oven animation } \\
\text { Healthy snacks program menu for a food bank } \\
\text { Healthy eating manual for chefs at women's drop-in } \\
\text { Diabetes education \& developmental disability project } \\
\text { Harm reduction approach to diabetes education project }\end{array}$ \\
\hline
\end{tabular}




\section{Instructors' profiles}

Instructors in early iterations of the course included women dietitian colleagues from diverse backgrounds, including working in public health, corporate nutrition promotion, food services, and community health centers, among others.

DCC is a cis, white settler environmental and public health physician with a long history of research on agri-food systems globally. He is also a member of a small-holder ecological, multi-crop, family farm on Chippewa-Haudenosaunee territories of the Saugeen river watershed in Grey County. He co-taught the course in the early years discussed here, and then shifted to a guest speaker.

EN is a settler and immigrant of Chinese ancestry living and working Toronto, covered by Treaty 13 signed with the Mississaugas of the Credit. A dietitian, graduate student, and lecturer of the program with work experiences in public health and health equity, his research interests include neoliberalism and social justice issues in food and health policy. He led the course for the latter years, coordinating the guest lectures, arranging field visits, liaising with community organizations on student projects, and assessing learning.

\section{Our critical approach to teaching food systems}

We developed a critical approach to teaching and learning in this food system course. Our understanding of critical borrows from the components of critical food studies by Koç et al. (2017), critical dietetics by Gingras et al. (2014), critical food pedagogies by Sumner (2015), and the value-based approach by Galt et al. (2012).

First, we seek to provide alternatives to positivism in public health nutrition. Positivism asserts that knowledge and learning are only objective, empirical, and value-neutral (Galt et al., 2012; Gingras et al., 2014). On the other hand, the value-based approach by Galt et al. (2012) acknowledges that values shape the decisions we make about our food systems, and that values influence food systems education. Recognizing that knowledge can be generated through experience by community members and students themselves, in a constructivist approach to teaching, students learn from existing knowledge and build upon their lived experiences (Seatter \& Ceulemans, 2017; Levkoe et al., 2014). We encouraged our students to reflect on their existing knowledge and experiences as part of food systems.

Second, food systems are power-laden at each stage, from production to waste. They are implicated in dominant sociopolitical structures that are often hidden and normalized (Sumner, 2015). These unequal structures of power shape food systems in ways that differentially benefit 
some while harming others. We provided opportunities for our students to uncover the powerrelationships among organizations and actors within our food systems, from harvesting to food waste, from migrant farm workers to multinational food distributors. Power differences also permeate the classroom setting through teacher-student relationships (Friere, 2018). By not treating students as passive recipients of knowledge, we engaged in dialogue with students as colleagues based on our experiences (Seatter \& Ceulemans, 2017). By making the classroom less hierarchical, we aimed to empower students to take more control of their learning.

Third, as instructors, we situated ourselves within food systems by practicing reflexivity (Gingras et al., 2014). Reflexivity is a way to understand our own perspectives and close the distance between ourselves and the field of study (Gingras et al., 2014). Our values and positionalities shape our interactions with the food systems; they also influence why and how we teach food systems. For example, EN's work in social justice advocacy as an immigrant, and DCC's research in global agri-food systems and as a member of a family farm influenced each of them. By modeling this practice, we intended to promote reflexivity among students (Moon, 2001). Also, experiential learning such as field visits and community projects provided opportunities for students to locate themselves within food systems at different scales and reflect on their roles as future food system professionals (Ash \& Clayton 2009; Levkoe et al., 2014; Valley et al., 2018).

Fourth, critical approaches call for social change to our food systems, change that addresses structures of power, particularly in globalized capitalist systems (Koç et al., 2017; Sumner, 2016). Koç et al. (2017) describe this approach as part of the "activist orientation within Food Studies to transform the food system and society at large (p.6)." We believe in fostering change through learning that is transformative (Halman et al. 2017). Transformative learning is "a process by which adults learn how to think critically for themselves rather than take assumptions supporting a point of view for granted" (Mezirow, 2006, p.103). As food educators, we agreed that "we feel we must change the way we teach to improve student learning - $\mathrm{t} o$ facilitate their transformation into active knowledge producers, engaged citizens, and democratic members of our global community - to ultimately change the food system and the world" (Galt et al., 2013, p.140).

\section{Methods}

As co-instructors, we reflected on our teaching experience through a series of steps. In 2017, we reviewed students' assignments and discussed our experiences with the course to present our and colleagues' experience with "experiential-reflective learning in a graduate dietetic food systems course" at the Annual Meeting of the Canadian Association of Food Studies in Toronto (Ng et al., 2017). As the course offered in this integrated format concluded in 2019, we met to reflect on our cumulative experiences from 2015 to 2019. About ninety students took the course over the five years. 
Individually, we each reviewed students' assignments from the respective cohorts we taught and selected specific assignments based on our experiences and perspectives. We then sought permissions from respective students whose assignments we selected. In addition, feedback by students were gathered through an open discussion with students at the end of the course each year, where students could provide comments on specific components of the course. We also reviewed anonymous individual course evaluations where students had the opportunity to share their own learning and concerns without fear of repercussion.

We brought the selected materials and evaluations together for joint dialogue and reflection (Brookfield, 2017). From this process, several key areas of learning and challenges emerged. We then revisited the materials we collected to exemplify and refine these themes through an iterative process. Three key interconnected areas of learning were identified: intentions, facilitation, and tensions.

\section{Areas of learning}

\section{Intentions}

Co-instructors incorporated critical approaches to fill the gap within the competency-based curriculum by addressing critical consciousness and social responsibility, as noted by Halman et al. (2017). The food systems became not only the "object of learning but also the vehicle for learning" (Flowers \& Swan, 2012, p.423). Our intentions were to expand the role of dietitians as nutrition experts and to solidify the connections between dietetic practice and food systems. Although we provided a template of stages from food production inputs to waste, we wanted to go beyond simply describing food systems to our students. Rather, we encouraged our students to situate themselves within food systems, beyond consumer, worker, or observer expert roles, to find gaps, and to imagine opportunities for change. Concepts were integrated into the weekly discussions to facilitate connections to social and ecological dimensions of food systems. Topics such as migrant farm workers, industrial food production, and food justice advocacy were selected to elicit awareness and reactions from students (Sipos et al., 2008).

\footnotetext{
"A national food retailer is large enough to interact directly with farmers rather than relying on the Food Terminal for procurement, while smaller operations have to create partnerships with farmers at the food terminal in order to purchase products." (2015 Assignment)

"As a dietitian, it is important to consider the ethical implications of promoting the consumption of foods which are not sustainable." (2018 Assignment)
} 
During an in-class activity, students were asked to trace the flow of a food commodity, e.g., rice or apples, from food production to consumption. Students realized the complexity of the food systems across the globe, of which they were previously unaware.

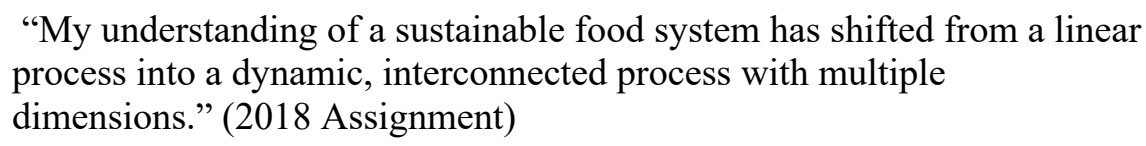

While they mapped out these commodity flows, issues of sustainability and equity within our current system surfaced. Students were asked to question the multiple purposes of food systems beyond nutrition, such as trade, food security, and social justice.

A string of field visits can sometimes feel siloed and disconnected. To address this concern, an in-class debriefing session was scheduled mid-way through the term. Dialogue among the learner, teacher, and knowledge (Setter \& Ceulemans, 2017) was facilitated to support the consolidation of learnings and the meaning-making process. Students began recognizing the complexity of food systems while locating the role of dietitians within them.

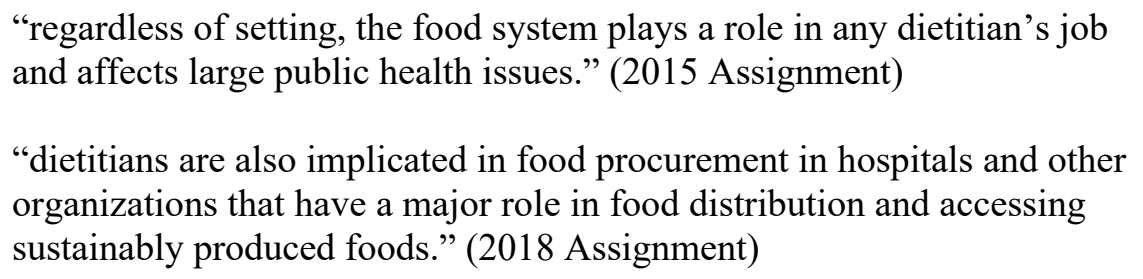

In addition to field visits, community-based projects, or service-learning is highly valued in sustainability education (Galt et al., 2012, 2013; Levkoe et al., 2014). It provides students opportunities to connect theory with real-life organizations, actors, and initiatives, and to concretize food systems concepts (Levkoe et al., 2014).

"Hands-on experiences to interact with people working in the field is very valuable." (2018 Evaluation)

Most projects were rooted in a community organization that serves marginalized populations with a social justice mandate. These included engaging with local residents about the utilization of a shared oven at a community farm serving a racialized neighbourhood, creating a healthy eating guide for cooks working at a women's drop-in center serving women in distress, and writing an advocacy letter for a local food security advocacy group to a local politician. These projects also introduced students to social actors (individuals and organizations) who were active in social change and advocacy (Meek \& Tarlau, 2016).

"Speaking to the community leaders really challenged my critical thinking and makes my learning more practical." (2017 Evaluation) 
Student evaluations consistently indicated that interacting with leaders in the field deepened their reflection and practical learning. However, these experiences often led tensions to surface.

\section{Tensions}

We understood tensions as the conflict, dissonance, or discomfort experienced during critical reflection processes. Educators have noted this integral and necessary mechanism for fostering critical consciousness through transformative learning in sustainable food systems courses (Galt et al., 2012) and health professional education (Halman et al., 2017). Mezirow (2006) refers to this process as the "disorienting dilemma" resulting from reflection. As one student said:

"I came across this extremely convoluted diagram of the global food system and thought that it perfectly illustrated why it's easy to feel overwhelmed when brainstorming ways to make improvement or increase its efficiency. There are so many paradoxes in our food system that cloud its current state, and complicate attempts to make improvements." (2015 Assignment)

Halman et al. (2017) suggest that "cognitive disequilibrium leads to students examining their values and beliefs" (p.18). These tensions, however, can seem unfamiliar and amplified in nutrition, a field rooted in the traditional biomedical model, expert-orientation, and positivist way of learning-knowing (Gingras et al., 2014). Galt et al. (2013) noted while self-reflection can be difficult for some students, the dissonance students realize by noting the gap between "what is and what should be" (p.136) propels students to take action and challenge the status quo. As one student noted:

"I feel obligated to understand how food is produced, and what consequences my recommendations have on not only the health of the general population, but also on the agri-food sector and our environment. However, I'm facing a challenge in my pursuit of understanding the food system - the more I learn about it, the less I seem to know." (2015 Assignment)

Experiential learning itself does not automatically lead to critical reflection (Yamashita \& Robinson, 2016); it needs to be guided intentionally. Reflection assignments can be effective in allowing moments of tension students are experiencing to surface. It is one of the most common evaluation methods used in transformative learning in higher education literature (Galt et al., 2013; Sumner, 2015; Levkoe et al., 2014). Reflective writing provides opportunities for students to connect their thoughts, experience, and emotion from the learning process. 
Sipos et al. (2008) refer to this process as engaging with the "head, hands, and heart" in transformative learning. It provides educators with a window on students' learning process (Galt et al., 2012) and clarifying self-appraisals:

"I myself was guilty of not thinking of the farm workers, instead focusing more on the farm owners that tend to represent the farm at farmers' markets." (2016 Assignment)

We integrated reflection in this course in the form of a "book-ended" assignment on food system conception. At the beginning of the course, students were asked to create their understanding of the food systems visual using their own experience. At the end of the course, students updated the visual and reflected on changes they had made resulting from all aspects of their learning. Students reflected on changes in their understanding and commented on their role in promoting sustainable food systems. From our experiences and student reflection assignments, two primary forms of tension emerged.

First, tensions arise when students begin to realize that dietary advice has an unintended impact on the food systems. These unintended impacts are contradictory to their values for an equitable food system. For example, the complexity of promoting local food production or environmental impact of recommending increased fish consumption.

"I now recognize that even when produced locally, the demand for fresh produce 365 days of the year can be environmentally degrading depending on the type of production methods used." (2016 Assignment)

"I realize now seemingly benign decisions made by consumers can have global implications." (2016 Assignment)

"it will not matter if nutrition science finds health benefits from eating fish if we cannot sustain their stocks." (2016 Assignment)

Second, what are the roles of the dietitians in promoting sustainable and just food systems (Carlsson et al., 2020)? Students began to critically consider the limitations of providing nutrition information and individual counseling if structural and institutional power-relations are not addressed (Dharamsi et al., 2010).

'I believe a significant reason why the food systems' adverse effects on populations in other areas of the world remain largely unknown or ignored is because of how far removed they are from us and our daily lives. Conflict, for me, stems from the challenge of positioning myself in the realities of this system on a personal and professional level." (2019 Assignment) 
"My discomfort with capitalism has only grown through this time; however, I do see the value of working both within the industry and outside of it." (2019 Assignment)

Looking back at these three areas of learning, we reflected on the challenges and complexities of the socio-political act of teaching food systems critically at the university.

\section{Challenges and complexities}

Burnout is a "danger all activist-oriented teachers face" (Brookfield, 2017, p.56). Brookfield (2017) cautions us not to measure our teaching effectiveness with "fixing the system" (p.56). It is crucial to set realistic expectations about constraints and limitations with the context of one course. Transformative learning is an on-going and non-linear process. Often food systems concepts are only covered in a one-semester course within a degree program in dietetics. As dietetic programs are required to meet accreditation standards for many dietetic competencies, little room remains for topics outside the core practice competencies.

Students also come to the class from diverse backgrounds, values, and career aspirations. It is important to accept students where they are in their journey and their positionality while acknowledging our differences. Patience is needed as students' transformative learning continues well after the course; moments of critical insights can surface as they start their practice, or even years into it, as was the case with ourselves in our own careers. It takes additional efforts for us to let go of the power of the "all-knowing" teacher and stay with discomfort and tensions ourselves (Lordly et al., 2019).

As facilitators, we often need to let go of the control of the outcomes. Political, valueladen topics are especially challenging to facilitate. Facilitation skills applied around controversial issues are crucial for addressing conflict in a respectful, constructive, and meaningful manner. Effective facilitation requires being cognizant of our own values and areas of discomfort. Fostering an environment where students feel safe and supported is essential, especially around issues of race, gender, class, and colonialism (Lordly et al., 2019; Valley et al., 2018), as these issues are insufficiently addressed in much professional or even food systems training (Meek \& Tarlau, 2016). For example, some students were hesitant to talk about racism in the context of migrant farm worker regimes, when most workers are people of colour recruited from Mexico, Jamaica, and other Caribbean countries. Making racialized and Indigenous peoples visible in the food system and exploring the constraints they face was essential to us as instructors but provoked discomfort among some students (Yamashita \& Robinson, 2016). It is noteworthy that students increasingly recognized the impact of colonization on Indigenous food systems over the course of five years.

Conflicts can also occur during the discussion of topics such as regulation of food marketing by food industry actors and the influence of large corporations. Some students noted 
the power of industries to reach a large segment of the populations, while others pointed out the significant influence of large retailers on small producers. These were challenging discussions in class for educators using critical approaches, as different students held different beliefs and argued different perspectives in class. However, conflict can also advance knowledge through dialogue and reflection (Galt et al., 2012). Our ability to promote alternatives ways of knowing and multiple interpretations was key to meaningful class discussions related to social justice issues, aiming to help students feel safe to express their critiques without fearing that they would be dismissed (Lordly et al., 2019).

Where there are increasingly more food systems concepts included in dietetic education, a scan of syllabi in dietetic education programs in Canada by Fraser \& Brady (2019) revealed a lack of integration of social justice issues in the curriculum. Critical perspectives in addressing power, positivism, expert-orientation, and neoliberalism in health professional education are generally marginalized. In this landscape and the constraints of one course, resistance to fostering critical consciousness among students is to be expected. We have found that while most students learned to embrace systems thinking and complexities, only a few went deeper into the structures of power within our food systems. Rather than critical social change responses that addressed power (Galt et al., 2013), we often saw more consumer-based responses to food systems issues. These responses included educating individuals on products that are local or reading food labels to identify ultra-processed ingredients. This resistance to addressing power points to how dietetic education reflects the longstanding challenge within public health nutrition practice in shifting from individualistic understanding to structural and environmental approaches (Ashe, \& Sonnino, 2013; Raine, 2005).

While the development of critical consciousness was less clear, it is reasonable for many students to aspire to be health professionals helping others through their evidence-informed expertise based on their professional socialization process. Critical paradigms can be seen as being biased and not grounded in evidence. As health professionals, we have been taught not to "contaminate" our professional practice with our political values and personal biases (Galt et al., 2012; Gingras et al., 2014). This dominant ideology is reflected in how students fell back to individualistic approaches when considering the role of dietitians in everyday practice, despite shifts in perceptions of food systems.

Also, some students found it challenging to learn through "themes" such as complexity, industrialization, and food justice (Burns, 2013). Some preferred more concrete facts and technocratic solutions, while others found that the food systems course lacked focus (Seatter \& Ceulemans, 2017). As Brookfield noted, resistance is a natural part of the process, it is often beyond the control of the individual educators, and it is perhaps indicative of structures and institutions of power we brought up in class (Brookfield, 2017, p.52).

Lastly, critical approaches to teaching are often championed and maintained by individual practitioners and educators. The continuity of these pedagogical approaches can be made difficult by the focus on careerist competency-based structures and short-term contract teaching positions. 


\section{Conclusion}

With its benefits and limitations, teaching a food systems-oriented course in dietetics has been worthwhile. Many students commented on the need for such a course in the curriculum. They appreciated the connection to the land during their farm visits and learning about the realities of the communities they aspire to serve as dietitians through real-life projects.

Even though the course format has changed, course components described here can be integrated into existing courses or the overall curriculum within public health nutrition. First, field visits can connect students to the land, agriculture, and front-line workers in the food systems. Second, community-based real-life projects provide opportunities for experiential learning, critical reflection, and competency development. They do require long-term, meaningful engagement and relationship-building with organizations to ensure reciprocity and community ownership (Andrée et al., 2013; Levkoe et al., 2014). Third, reflection assignments are well-integrated in dietetic education programs. It remains an essential educational tool for the development of critical consciousness. Having specific instructions for students can guide students towards more critical reflections (Dharamsi et al., 2010). One example is Sipos et al. 's (2008) "head, hand, heart" model, where we can ask students to identify structures of power, relating learning to personal experience of dissonance, and reflecting on values of equity, social and ecological justice.

Several course components have been maintained or integrated within the program curriculum. Real-life projects have been transformed into a two-term culminating project to support achievement of dietetic training competencies in the management domain. Visits to community farms and gardens have been maintained and reflective practice is well-integrated into the overall program. Lastly, key food systems concepts such as sustainable food systems are covered by guest lectures, class discussions, and course readings. Beyond curriculum changes, our critical approach to teaching food systems can be meaningfully sustainable and fully integrated when, as food educators ourselves, we become critically aware of how our own values shape education and how we are embedded in structures and relations of power within food systems and universities. The "how" is sometimes more important than the "what."

We hope that this paper sparks further dialogue on how food educators can practice, model, and promote critical consciousness and reflexivity. Sharing our experience with this course can also address literature gaps identified in incorporating sustainability into curricula, specifically for a profession grounded in relationships to food (Harmon et al., 2011; Wegener, 2018). Further, dietetic practice is inherently pedagogical, with clear "educational aims"; it is often situated in influential organizations implicated in educating the public about food, including industries, hospitals, and governments (Flowers \& Swan, 2012, p.420). As our students become dietitians, we can hope that our modeling and their learning can be incorporated into the food education which they provide, exploring the limits of the organizational, social, and ecological contexts in which they practice. 
Acknowledgments: We thank the former and current faculty members of the Master of Public Health Nutrition \& Dietetics Program at the University of Toronto. We also appreciate our former students' willingness to share their course feedback and reflection assignments.

\section{References}

Andrée, P., Chapman, D., Hawkins, L., Kneen, C., Martin, W., Muehlberger, C., Nelson, C., Pigott, K., Qaderi-Attayi, W., Scott, S., \& Stroink, M. (2014). Building effective relationships for community-engaged scholarship in Canadian food studies. Canadian Food Studies, 1(1), 27-53. https://doi.org/10.15353/cfs-rcea.vli1.19

Ashe, L. M., \& Sonnino, R. (2013). At the crossroads: new paradigms of food security, public health nutrition and school food. Public health nutrition, 16(6), 1020-1027. https://doi.org/10.1017/S1368980012004326

Ash S.L., \& Clayton, P.H. (2009). Generating, deepening, and documenting learning: the power of critical reflection in applied learning. Journal of Applied Learning in Higher Education, 1(Fall), 25-48.

Brookfield, S. D. (2017). Becoming a critically reflective teacher ( $2^{\text {nd }}$ ed.). Jossey-Bass.

Burns, H. (2013). Meaningful sustainability learning: A study of sustainability pedagogy in two university courses. International Journal of Teaching and Learning in Higher Education, 25(2), 166.

Carlsson, L., Callaghan, E., \& Broman, G. (2019). How can dietitians leverage change for sustainable food systems in Canada? Canadian Journal of Dietetic Practice and Research, 80(4), 164-171. https://doi.org/10.3148/cjdpr-2019-005

Carlsson, L., Seed, B., \& Yeudall, F. (2020). The Role of Dietitians in Sustainable Food Systems and Sustainable Diets. Toronto: Dietitians of Canada. https://www.dietitians.ca/DietitiansOfCanada/media/Documents/Resources/SustainableFood-Systems-Dietitians-Roles-(Role-Paper).pdf

Cole, D.C., Parkes, M., Saint-Charles, J., Webb, J., Gislason M., McKellar, K., and the Canadian Community of Practice in Ecosystem Approaches to Health Team. (2018). Evolution of capacity strengthening: insights from the Canadian Community of Practice in Ecosystem Approaches to Health. Transformative Dialogues, 11(2), 1-21.

Dietitians of Canada. (2020). How to Become a Dietitian. https://www.dietitians.ca/Become-aDietitian/Education-and-Training

Dharamsi, S., Espinoza, N., Cramer, C., Amin, M., Bainbridge, L., \& Poole, G. (2010). Nurturing social responsibility through community service-learning: Lessons learned from a pilot project. Medical Teacher, 32(11), 905-911. https://www.doi.org/10.3109/01421590903434169 
Ferro-Townsend, S. (2011). Food for Thought: Reimagining the Ontario Food Terminal. [Unpublished Masters thesis]. University of Waterloo.

Flowers, R., \& Swan, E. (2012). Introduction: Why food? Why pedagogy? Why adult education? Australian Journal of Adult Learning, 52(3), 419-433.

Fraser, K., \& Brady, J. (2019). Exploring social justice advocacy in dietetic education: A content analysis. Canadian Journal of Dietetic Practice and Research, 80(1), 2-7. https://doi.org/10.3148/cjdpr-2018-027

Freire, P. (2018). Pedagogy of the oppressed: 50th anniversary edition. Bloomsbury.

Galt, R. E., Parr, D., Van Soelen Kim, J., Beckett, J., Lickter, M., Ballard, H. (2013). Transformative food systems education in a land-grant college of agriculture: The importance of learner-centered inquiries. Agriculture and Human Values, 30(1), 129-142. https://www.doi.org/10.1007/s10460-012-9384-8

Galt, R., Clark, S. \& Parr, D. (2012). Engaging values in sustainable agriculture and food systems education: Toward and explicitly values-based pedagogical approach. Journal of Agriculture, Food Systems, and Community Development, 2(3), 43-54. https://www.doi.org/10.5304/jafscd.2012.023.006

Gingras, J., Asada, Y., Fox, A., Coveney, J., Berenbaum, S., \& Aphramor, L. (2014). Critical dietetics: A discussion paper. Journal of Critical Dietetics, 2(1), 2-12.

Halman, M., Halman, M., Baker, L., Baker, L., \& Ng, S. (2017). Using critical consciousness to inform health professions education: A literature review. Perspectives on Medical Education, 6(1), 12-20. https://www.doi.org/10.1007/s40037-016-0324-y

Harmon, A., Lapp, J. L., Blair, D., \& Hauck-Lawson, A. (2011). Teaching food system sustainability in dietetic programs: Need, conceptualization, and practical approaches. Journal of Hunger \& Environmental Nutrition, 6(1), 114-124. https://www.doi.org/10.1080/19320248.2011.554272

Koç, M., Bancerz, M., \& Speakman, K. (2017). The interdisciplinary field of food studies. In M. Koç, J. Sumner, \& A. Winson (Eds), Critical Perspectives in Food Studies (2 ${ }^{\text {nd }}$ ed.) (pp. 318). Oxford University Press.

Levkoe, C. Z., Brail, S., \& Daniere, A. (2014). Engaged pedagogy and transformative learning in graduate education: A service-learning case study. The Canadian Journal of Higher Education, 44(3), 68. https://doi.org/10.47678/cjhe.v44i3.186039

Lordly D., Lövestam E., \& Ruhl J. (2019). Awakening the possibilities: An exploration of critical nutrition and dietetic training and education. In J. Coveney, \& S. Booth (Eds), Critical Dietetics and Critical Nutrition Studies (pp. 43-67). Springer.

Meek, D., \& Tarlau, R. (2016). Critical food systems education (CFSE): educating for food sovereignty. Agroecology and Sustainable Food Systems, 40(3), 237-260. https://doi.org/10.1080/21683565.2015.1130764

Mezirow, J. (2006). An overview on transformative learning. In J. Crowther, \& P. Sutherland, (Eds). Lifelong Learning (pp. 24-38). London: Routledge. https://doi.org/10.4324/9780203936207 
Moon, J. (2001). Reflection in Higher Education Learning. LTSN Generic Centre PDP Working Paper 4. https://www.brandeis.edu/experientiallearning/currentpdfs/reflectioninhighered.pdf

Ng, E., Cole, D.C., Fox, A. (2017, June). Experiential-reflective learning in a graduate dietetics food systems course. Workshop presented at the Annual meeting Conference of Canadian Association of Food Studies, Toronto.

Partnership for Dietetic Education and Practice (PDEP). (2013). Integrated competencies for dietetic education and practice. https://www.pdep.ca/library/Accreditation-Policies-andStandards/PDEP-ICDEP-2013-.aspx

Raine K. D. (2005). Determinants of healthy eating in Canada: an overview and synthesis. Canadian Journal of Public Health, 96(S3), S8-S15. https://doi.org/10.1007/BF03405195

Seatter, C. S., \& Ceulemans, K. (2017). Teaching sustainability in higher education: Pedagogical styles that make a difference. The Canadian Journal of Higher Education, 47(2), 47.

Sipos, Y., Battisti, B., \& Grimm, K. (2008). Achieving transformative sustainability learning: Engaging head, hands, and heart. International Journal of Sustainability in Higher Education, 9(1), 68-86. https://www.doi.org/10.1108/14676370810842193

Sumner, J. (2015). Learning to eat with attitude: critical food pedagogies. In R. Flowers \& E. Swan (Eds), Food Pedagogies (pp. 201-213). Rutledge.

Sumner, J. (2016). Learning, food and sustainability. Palgrave MacMillan.

University of Toronto. (2020). MPH Nutrition \& Dietetics. https://www.dlsph.utoronto.ca/program/mph-nutrition-and-dietetics/

Valley, W., Wittman, H., Jordan, N., Ahmed, S., \& Galt, R. (2018). An emerging signature pedagogy for sustainable food systems education. Renewable Agriculture and Food Systems, 33(5), 467-480. https://doi.org/10.1017/S1742170517000199

Wegener, J. (2018). Equipping future generations of registered dietitian nutritionists and public health nutritionists: A commentary on education and training needs to promote sustainable food systems and practices in the 21st century. Journal of the Academy of Nutrition and Dietetics, 118(3), 393-398. https://www.doi.org/ 10.1016/j.jand.2017.10.024

Wegener, J., Fong, D., \& Rocha, C. (2018). Education, practical training and professional development for public health practitioners: a scoping review of the literature and insights for sustainable food system capacity-building. Public Health Nutrition, 21(9), 1771-1780. https://www.doi.org/10.1017/S1368980017004207.

Weiler, A., McLaughlin, J., Cole, D. (2017). Food security at whose expense? A critique of the Canadian temporary farm labour migration regime and proposals for change. International Migration, 55(4), 48-63. https://doi.org/10.1111/imig.12342

Yamashita, L., \& Robinson, D. (2016). Making visible the people who feed us: Educating for critical food literacy through multicultural texts. Journal of Agriculture, Food Systems, and Community Development, 6(2), 269-281. https://www.doi.org/10.5304/jafscd.2016.062.011 